\title{
Pro-poor policies and improvements in maternal health outcomes in India
}

\author{
M. Bhatia ${ }^{1 *}$ D, L. K. Dwivedi ${ }^{2}$, K. Banerjee ${ }^{2}$, A. Bansal ${ }^{2}$, M. Ranjan $^{3}$ and P. Dixit ${ }^{4}$
}

\begin{abstract}
Background: Since 2005, India has experienced an impressive $77 \%$ reduction in maternal mortality compared to the global average of $43 \%$. What explains this impressive performance in terms of reduction in maternal mortality and improvement in maternal health outcomes? This paper evaluates the effect of household wealth status on maternal mortality in India, and also separates out the performance of the Empowered Action Group (EAG) states and the Southern states of India. The results are discussed in the light of various pro-poor programmes and policies designed to reduce maternal mortality and the existing supply side gaps in the healthcare system of India. Using multiple sources of data, this study aims to understand the trends in maternal mortality (1997-2017) between EAG and non EAG states in India and explore various household, economic and policy factors that may explain reduction in maternal mortality and improvement in maternal health outcomes in India.
\end{abstract}

Methods: This study triangulates data from different rounds of Sample Registration Systems to assess the trend in maternal mortality in India. It further analysed the National Family Health Surveys (NFHS). NFHS-4, 2015-16 has gathered information on maternal mortality and pregnancy-related deaths from 601,509 households. Using logistic regression, we estimate the association of various socio-economic variables on maternal deaths in the various states of India.

Results: On an average, wealth status of the households did not have a statistically significant association with maternal mortality in India. However, our disaggregate analysis reveals, the gains in terms of maternal mortality have been unevenly distributed. Although the rich-poor gap in maternal mortality has reduced in EAG states such as Bihar, Odisha, Assam, Rajasthan, the maternal mortality has remained above the national average for many of these states. The EAG states also experience supply side shortfalls in terms of availability of PHC and PHC doctors; and availability of specialist doctors.

(Continued on next page)

\footnotetext{
* Correspondence: m.r.bhatia@lse.ac.uk

'Department of Health Policy, London School of Economics and Political

Science, Houghton Street, London WC2A 2AE, UK

Full list of author information is available at the end of the article
}

(c) The Author(s). 2021 Open Access This article is licensed under a Creative Commons Attribution 4.0 International License, which permits use, sharing, adaptation, distribution and reproduction in any medium or format, as long as you give appropriate credit to the original author(s) and the source, provide a link to the Creative Commons licence, and indicate if changes were made. The images or other third party material in this article are included in the article's Creative Commons licence, unless indicated otherwise in a credit line to the material. If material is not included in the article's Creative Commons licence and your intended use is not permitted by statutory regulation or exceeds the permitted use, you will need to obtain permission directly from the copyright holder. To view a copy of this licence, visit http://creativecommons.org/licenses/by/4.0/ The Creative Commons Public Domain Dedication waiver (http://creativecommons.org/publicdomain/zero/1.0/) applies to the data made available in this article, unless otherwise stated in a credit line to the data. 


\begin{abstract}
(Continued from previous page)
Conclusions: The novel contribution of the present paper is that the association of household wealth status and place of residence with maternal mortality is statistically not significant implying financial barriers to access maternal health services have been minimised. This result, and India's impressive performance with respect to maternal health outcomes, can be attributed to the various pro-poor policies and cash incentive schemes successfully launched in recent years. Community-level involvement with pivotal role played by community health workers has been one of the major reasons for the success of many ongoing policies. Policy makers need to prioritise the underperforming states and socio-economic groups within the states by addressing both demand-side and supplyside measures simultaneously mediated by contextual factors.
\end{abstract}

Keywords: Maternal health, Maternal mortality, Maternal health outcomes, Financial incentives, Conditional cash transfers, Demand side financing, Developing countries, India

\section{Background}

It is estimated that nearly 303,000 women die per year from maternal causes with almost all of these deaths occurring in low-resource settings [1,2]. Given that most of these deaths can be easily prevented or treated with cheap and effective interventions, such high maternal mortality and morbidity is unacceptable even in resource constrained settings. It is therefore not surprising that reducing maternal mortality and morbidity has been an important concern for both national governments and international organizations. The risk of a woman dying as a result of pregnancy or childbirth during her lifetime is about one in six in the poorest parts of the world compared with about one in 30,000 in Northern Europe [3]. Such inequalities poses a huge challenge to meeting the post Millennium Development Goals (MDGs) in the era of Sustainable Development Goals (SDGs).

India is the world's largest democratic nation, with $16 \%$ of the global population. Unfortunately, India has the highest number of maternal deaths in the world, contributing a total of 45,000 maternal deaths in 2015 [4]. It is one of the six countries that contributes to $50 \%$ of the world's maternal mortality [4]. Healthcare in India is the responsibility of individual states, which vary in terms of their level of socio-economic development, size of population, experience of epidemiological transition, and health system capacities, factors which influence the health status experienced by the population of the states. On one hand, states such as Kerala experience relatively low levels of maternal mortality which are comparable with developed countries, whereas a few of the states belonging to Empowered Action Group (EAG) (a group of socio-economically backward states), such as Madhya Pradesh and Uttar Pradesh suffer high maternal mortality comparable with some of poorest countries of the world [5]. Reduction in maternal mortality in India has been a very slow process but much more rapid decline has been observed in recent years.

A number of countries have adopted various strategies that have contributed to the decline in maternal mortality over the years, from a single intervention to a complex set of public health approaches like safe motherhood strategies promoted by WHO, and UNICEF [6]. These include strategies like ANC, delivery by trained personnel, promotion of institutional delivery, and access to emergency obstetric services by strengthening health systems, and addressing broader social determinants of maternal health. In addition, many countries are experimenting with demand side financing initiatives including the role of conditional cash transfers to reduce financial barriers in accessing maternal health services (8-16).

India's achievements in reduction of maternal mortality in recent years can be considered a success story as maternal mortality has declined over the years from 556 per 1000 live births in 1990 to 174 in 2015 at a rate of $15.8 \%$ annually [7]. Since 2005, India has experienced an impressive $77 \%$ reduction in maternal mortality compared to the global average of $43 \%$ [8]. In fact, this achievement has not gone unnoticed and India has been commended for this remarkable feat of drastically reducing maternal mortality by the WHO [8]. What explains this impressive performance in terms of reduction in maternal mortality and improvement in maternal health outcomes?

The present research has triangulated data from various sources and aims to examine the trends in maternal mortality (1997-2017) between EAG and non EAG states in India and explore various household, economic and policy factors that may explain reduction in maternal mortality and improvement in maternal health outcomes. The paper further focusses on evaluating the effect of household wealth status on maternal mortality in India. The results are discussed in the light of various demand side financing initiatives and pro-poor policies designed to reduce maternal mortality and the existing supply side gaps in the healthcare system of India. This paper is timely as India is still a major contributor to the maternal mortality and has initiated a number of demand side financing strategies targeted to poorer sections of the society, aimed at reducing maternal deaths. 


\section{Methods}

The primary objective of the study was to estimate the maternal deaths using the different sample surveys conducted in India. The data used in the study were derived from the series of Sample Registration System (SRS) and three round of National Family Health Survey (NFHS) NFHS-2, 1998-99, NFHS-3, 2005-06 and NFHS-4, 2015-16). NFHS provided micro-level data to understand the determinants of maternal mortality at the individual level whereas SRS was used to analyse trends in maternal mortality, as NFHS was unable to provide nationally representative reliable estimates for the same. The estimates available in SRS for India and major regions of the country based on 3 years' pooled data have been used to analyse the trend of maternal deaths from 1997 to 2017.

With respect to maternal deaths, household head was enquired about any female ( 12 years or older) who died during pregnancy, during child birth or within 2 months after the end of pregnancy or childbirth. Using this information available in household file, maternal mortality ratio /100000 live births across the various states of India has been estimated. Household file contains the information of all the household members, including age, sex, marital status, education, collected from the head of the household.

This is calculated for each state using the following formula:

$$
M M R_{i}=\frac{\text { No.of maternal deaths in the sample }}{\text { Total no.of live births in the sample }} X_{i} X 100,000
$$

Here,

$M M R_{i}=$ Maternal mortality Ratio of state 'i'

No. of maternal deaths in the sample $_{i}=$ Number of maternal deaths recorded among the sampled households in state 'i'

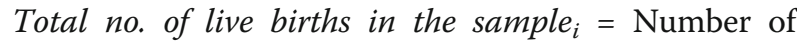
total live births recorded among the sampled households in state ' $\mathrm{i}$ '

For the retrospective information regarding maternity history of childbirth and death that took place 5 years prior to the survey, NFHS-4 Kids file was used in order to estimate institutional delivery for states of India. In addition, data on shortfall of health infrastructure and human resources have been taken from Rural Health Statistics, 2005 and 2015 to compare the supply-side infrastructure in India.

Like previous NFHS surveys, NFHS-4 provides information on population, health and nutrition for every State / Union territory in India. All women aged 15-49 years and men aged 15-54 years in the selected sample households were eligible for interviewing. NFHS-4 gathered information from 601,509 households, 699,686 women, and 103,525 men using four different questionnaires [9]. Retrospective information since January 2013 has been collected from head of households regarding the death of any member of the household.

\section{Analysis}

The outcome variable was maternal deaths which has been defined as " 1 " if a household had any maternal death/deaths and " 0 " otherwise. Place of residence, education level of household head, region of residence in four categories (EAG, Southern, North East, Rest of India), Wealth Index (WI), households with any insurance coverage, religion, caste, and household size were used as predictors. All the independent variables were categorized to get a sufficient sample of maternal deaths in each category. The details of these variables are available in Supplementary file Table A.1. The analysis for NFHS-4 was restricted to 23,637 households that reported any death in the household since January 2013.

Multivariate analysis was applied to find out the odds of a household to experience a maternal death event. In addition to multivariate analysis, funnel plots were drawn to compare the variation in performance between states on maternal mortality ratio (MMR) per 100,000 live births over time from NHFS-2 (1998-1999) to NFHS- 4 (2015-16). The all India average maternal mortality (indicated by a solid line parallel to the $\mathrm{x}$-axis) was used as a baseline reference. The 95 and 99\% confidence bands were constructed and each data point represents the state's maternal mortality and institutional deliveries. Also, scatter plots were drawn with each data point indicating the state position in relation to maternal mortality and difference poorest and the richest groups simultaneously.

Analysis was carried out using Stata 15.0 software.

\section{Results}

\section{Trends in maternal mortality and maternal health} indicators

The historical trend in maternal mortality ratio (MMR) in various groups of states in India from 1997 to 2017 is presented in Fig. 1. MMR has reduced in all regions of the country. In EAG states and Assam, which are considered to be poor performing states in terms of human development and public health, MMR has relatively declined by $66 \%$ in the last 20 years. For the better performing states of the Southern region, the relative rate of decline is $62 \%$ and for overall India, the relative rate of reduction in MMR in the last two decades is $69 \%$. This improvement is also observed with respect to maternal health indicators. 


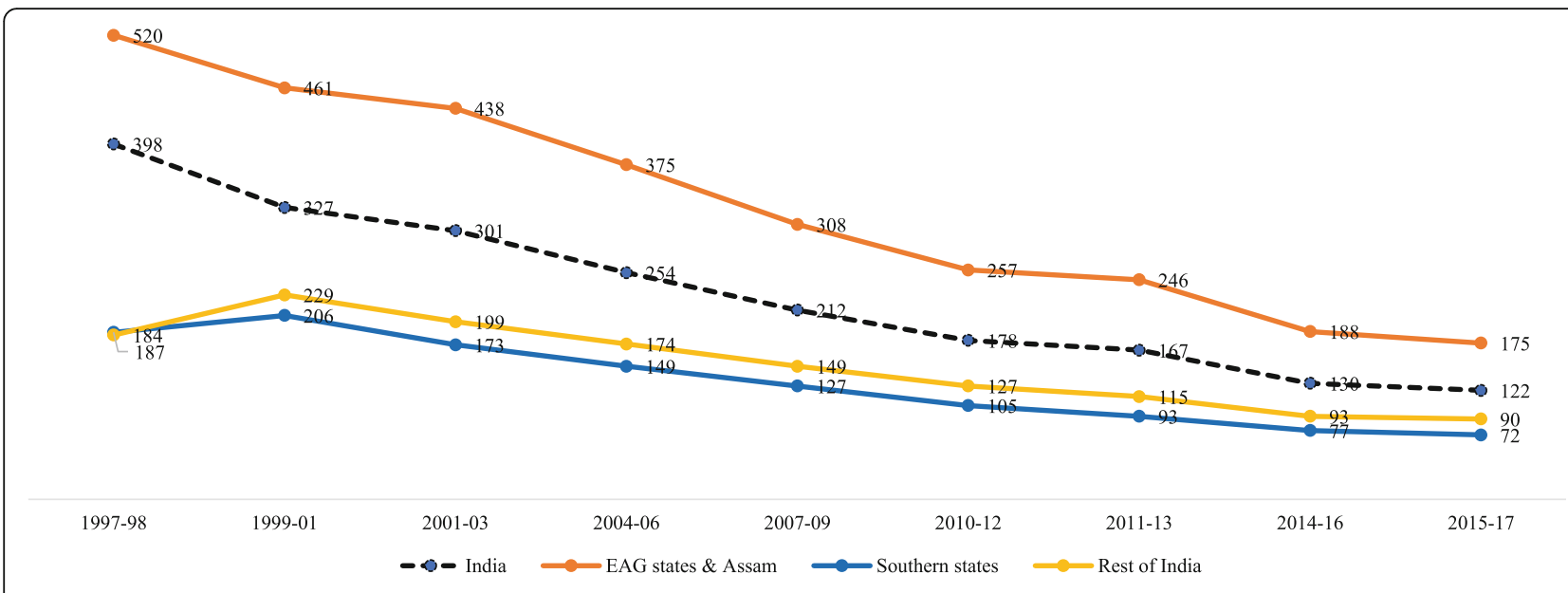

Data source: Special Bulletin on Maternal Mortality in India, Sample Registration System, 1997-2017

Fig. 1 Trend of Maternal Mortality Ratio (Maternal deaths per 100,000 live births) by state groups from 1997 to 2017 in India. Data source: Special Bulletin on Maternal Mortality in India, Sample Registration System, 1997-2017

Figure 2 provides changes in estimates of various maternal health indicators for women who have at least one live birth in the 5 years preceding the survey periods over the last NFHS decade, 2005-2016. ANC provided by skilled workers for the poorest women has increased by $5 \%$. The gap in ANC services by skilled professional between poorest and richest women has reduced over the study decade. The percentage of women who attained full ANC has increased from 12 to $21 \%$. The percentage of pregnant women with anaemia has reduced by $8 \%$ from
NFHS 3 to NFHS 4. Total unmet need of family planning has reduced marginally from 14 to $13 \%$. There is a vast decline in marriage of girls below 18 years, from $47 \%$ in NFHS 3 to $27 \%$ in NFHS 4 . The role of institutional delivery in improving maternal health in India is undeniable and widely documented. Institutional deliver has almost doubled from 2005 2006 to 2015-16. The rich-poor gap in institutional delivery has halved over the same decade. Post-natal care for mothers within $48 \mathrm{hrs}$ of delivery has almost doubled in the same period.

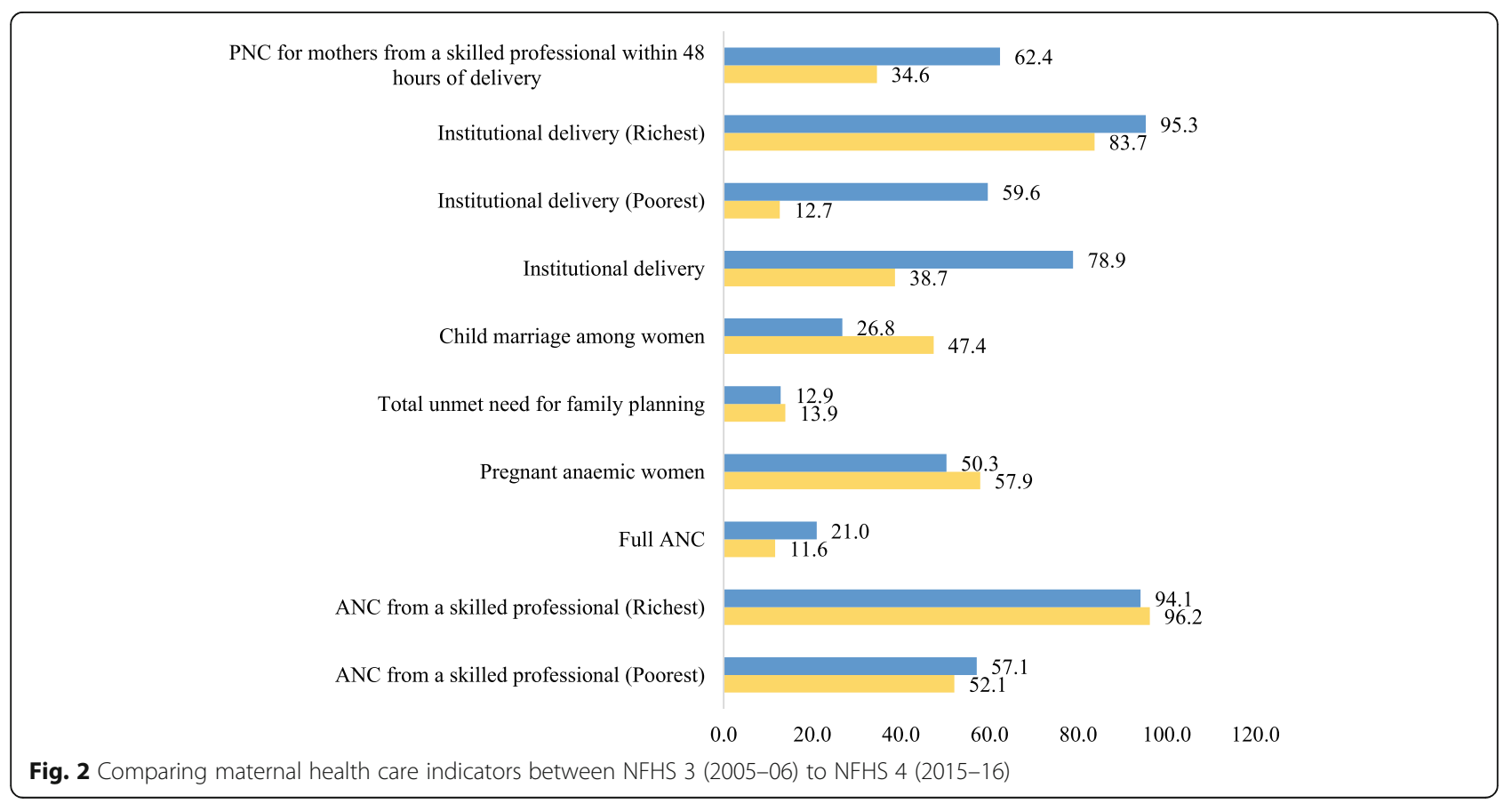




\section{Multivariate logistic regression, performance of states, and inequalities}

In Table 1 we present the background characteristics of households who experienced maternal death. Table 2 shows the results of multivariate logistic regression on households having any maternal deaths due to various factors in a household. Households having illiterate head of the household had two times higher odds of experiencing maternal deaths in comparison with the households where head of the household was highly educated $(p<$ $0.001)$. The risk of maternal deaths was $78 \%$ higher

Table 1 Background characteristics of those households $(\mathrm{HH})$ which experienced maternal death during 3 years prior to the survey, NFHS-4, 2015-16

\begin{tabular}{|c|c|c|}
\hline Covariates & $\mathbf{N}$ & Percentage \\
\hline \multicolumn{3}{|l|}{ Place of Residence } \\
\hline Urban & 6095 & 1.87 \\
\hline Rural & 17,542 & 2.60 \\
\hline \multicolumn{3}{|l|}{ Education level of $\mathrm{HH}$ head } \\
\hline Higher & 2117 & 1.15 \\
\hline Illiterate & 6822 & 3.34 \\
\hline Primary & 4504 & 2.70 \\
\hline Secondary & 10,194 & 1.87 \\
\hline \multicolumn{3}{|l|}{ Region of residence } \\
\hline Southern states & 2617 & 1.13 \\
\hline EAG states & 14,011 & 3.33 \\
\hline North-east & 1684 & 2.42 \\
\hline Rest of India (western+ Northern+west Bengal) & 5325 & 1.59 \\
\hline \multicolumn{3}{|l|}{ Wealth Index } \\
\hline Richest & 4138 & 1.26 \\
\hline Poorest & 5181 & 4.10 \\
\hline Poorer & 5170 & 2.30 \\
\hline Middle & 4930 & 2.52 \\
\hline Richer & 4218 & 1.57 \\
\hline \multicolumn{3}{|l|}{$\mathrm{HH}$ any health Insurance coverage } \\
\hline Yes & 6093 & 1.49 \\
\hline No & 17,544 & 2.74 \\
\hline \multicolumn{3}{|l|}{ Religion } \\
\hline Hindu & 18,428 & 2.37 \\
\hline Non-Hindu & 5209 & 2.45 \\
\hline \multicolumn{3}{|l|}{ Caste } \\
\hline SC/ST & 7930 & 3.00 \\
\hline Others & 15,707 & 2.13 \\
\hline \multicolumn{3}{|l|}{ HH Size } \\
\hline Less than 5 & 10,862 & 2.12 \\
\hline more than or equal to 5 & 12,775 & 2.62 \\
\hline Total & 23,637 & 2.38 \\
\hline
\end{tabular}

among those households where the head of the household was educated up to primary level in comparison to households where the head was highly educated $(p<$ 0.05). The odds of maternal deaths in EAG states was two times in comparison to the Southern states ( $p<$ $0.05)$. The poorest households were $80 \%$ more likely to experience maternal deaths in comparison to the richest households. However, it is important to note that except for the households belonging to the lowest wealth quintile, the odds ratios were not significant. Further, the households which were not covered under any health insurance scheme were $35 \%$ more likely to experience maternal deaths in comparison to those who were covered $(p<0.05)$. It may also be noted that additional multivariate logistic regression (not shown) confirmed that same set of factors namely, illiterate head of households, and households with no health insurance, are two important determinants of adverse maternal health outcomes in both the poor and richer states of India. Religion of the household, and number of members in the household show no significant effect on the maternal deaths in India. The odds of maternal deaths was found to be lower among households belonging to non-SC/ST castes than SC/ST households $(p<0.10)$.

In addition to the logistic regression, we analysed the performance of the various states with respect to MMR and the inequalities between the richest and poorest wealth quintiles within the states. Figure 3 provides funnel plots indicating the level of MMR by total births sampled in NFHS 4 (2015-16) and assesses the variation in performance of the various states. This figure helps to identify the states with the lowest and highest MMR, compared with the Indian average (referral line) used as a baseline to compare each state with. The plots closer to the $y$-axis are states with low numbers of sampled births and those to the right are states with high births. Those states outside the $99 \%$ CI or $95 \%$ CI can be considered as outliers in terms of their MMR. States which are above the Indian average are the worseperforming states and those below are the betterperforming states. It can be observed from Fig. 3 that Madhya Pradesh, Bihar, Uttar Pradesh and Eastern states like Tripura and Assam have performed poorly (State codes in Table A.2). Most of the Southern states are found in the lower side of the funnel plot, indicating low MMR. Analysis over 18 years from NHFS-2 (not shown) reveals that EAG states including Assam have consistently under-performed over the years. It may also be noted that those states which experienced high MMR also had lower institutional deliveries.

Figure 4 shows the scatterplot of the difference in MMR by top $20 \%$ richest and bottom $20 \%$ poorest and MMR across various states of India. The states Madhya 
Table 2 Results of multivariate logistic regression of effects of various covariates on maternal deaths, NFHS-4, 2015-16

\begin{tabular}{|c|c|c|c|}
\hline \multirow[b]{2}{*}{ Covariates } & \multirow[b]{2}{*}{ Odds Ratio } & \multicolumn{2}{|c|}{ 95\% Confidence interval (Cl) } \\
\hline & & Lower Limit & Upper Limit \\
\hline \multicolumn{4}{|l|}{ Place of Residence } \\
\hline Urban & 1.00 & & \\
\hline Rural & 1.04 & 0.83 & 1.30 \\
\hline \multicolumn{4}{|l|}{ Education level of $\mathrm{HH}$ head } \\
\hline Higher & 1.00 & & \\
\hline Illiterate & $2.26^{* * *}$ & 1.45 & 3.52 \\
\hline Primary & $1.78^{* *}$ & 1.13 & 2.81 \\
\hline Secondary & 1.52 & 0.99 & 2.34 \\
\hline \multicolumn{4}{|l|}{ Region of residence } \\
\hline Southern states & 1.00 & & \\
\hline EAG states & $1.79^{* *}$ & 1.25 & 2.57 \\
\hline North-east & 1.50 & 0.94 & 2.42 \\
\hline Rest of India (Western+ Northern + West Bengal) & 1.05 & 0.70 & 1.58 \\
\hline \multicolumn{4}{|l|}{ Wealth Index } \\
\hline Richest & 1.00 & & \\
\hline Poorest & $1.80^{* *}$ & 1.26 & 2.59 \\
\hline Poorer & 1.37 & 0.97 & 1.96 \\
\hline Middle & 1.33 & 0.95 & 1.89 \\
\hline Richer & 1.17 & 0.83 & 1.66 \\
\hline \multicolumn{4}{|l|}{$\mathrm{HH}$ any health Insurance coverage } \\
\hline Yes & 1.00 & & \\
\hline No & $1.35^{* *}$ & 1.10 & 1.66 \\
\hline \multicolumn{4}{|l|}{ Religion } \\
\hline Hindu & 1.00 & & \\
\hline Non-Hindu & 1.19 & 0.97 & 1.47 \\
\hline \multicolumn{4}{|l|}{ Caste } \\
\hline SC/ST & 1.00 & & \\
\hline Others & $0.84^{*}$ & 0.71 & 1.01 \\
\hline \multicolumn{4}{|l|}{ HH Size } \\
\hline Less than 5 & 1.00 & & \\
\hline More than equal to 5 & 1.10 & 0.94 & 1.30 \\
\hline
\end{tabular}

${ }^{*} p<0.10 ;{ }^{* *} p<0.05 ;{ }^{* * *} p<0.001$

Pradesh, Tripura and Uttar Pradesh fall in the top right quadrant indicating that these states are poor performers both in terms of having relatively high MMR and also high gap between richest and poorest wealth quintiles. The figure also shows that states like Andhra Pradesh, West Bengal, Maharashtra, Meghalaya, Mizoram, and Jammu \& Kashmir with low MMR but high inequality between the poorest and richest quintiles. Odisha and Rajasthan has shown impressive improvement in lowering their MMR and inequality post 2005. States like Goa, Himachal Pradesh, Karnataka, Kerala, Tamil Nadu, and Kerala had consistently performed well and are excellent examples of low MMR with low poorest-richest gap.

\section{Supply-side constraints: PHC and CHC}

For the successful implementation of any maternal health programme, understanding the role of supply-side factors, namely health facilities and human resources is vital. Figure A.1 shows that the gap in shortfall of PHC in rural areas of EAG states and Assam has remained significantly higher than the rest of India. The shortfall has been estimated as the difference between number of PHCs in position in the particular year and the number of PHCs required in the area as per the population norms. The graph implies that in 2018 there was a shortage of 4294 PHCs in EAG states and Assam compared to only 175 in South Indian States. The gap in 


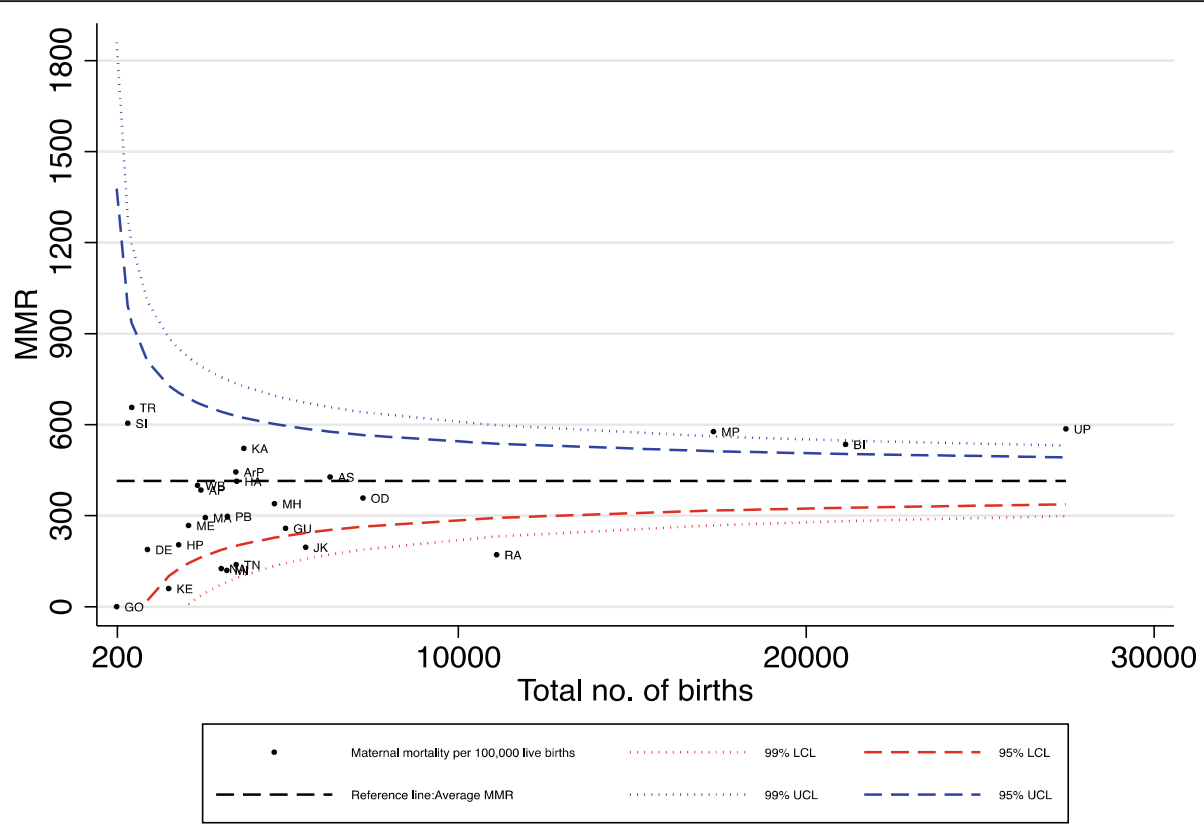

Fig. 3 Maternal mortality per 100,000, India, 2015-16(NFHS 4). Note: State codes in Supplementary Table A.2. The following states are merged together for NFHS 4: Andhra Pradesh and Telangana, Madhya Pradesh and Chhattisgarh, Bihar and Jharkhand, Uttar Pradesh and Uttarakhand. UTs are dropped from this figure

shortfall of PHCs between the poor performing states (EAG states and Assam) and the better performers (Southern states) has almost doubled from 2004 to 2018.

Finally, Fig. 5 shows shortfall of doctors in PHCs, specialists in CHCs and ANMs from 2005 to 2015. As per the Indian Public Health Standard (IPHS) norms, a minimum of one MBBS doctor should be present in a PHC. Overall, the shortfall in doctors has increased in India. EAG states and Assam contributed majority of the increase in the shortfall of doctors in 2015. As per the revised IPHS norms, the minimum number of specialists required in CHCs is five: General Surgeon, Physician, Obstetrician \& Gynaecologist, Paediatrician, and Anaesthetist. The shortfall in specialists in CHCs has tripled from 2005 to 2015 . Almost 50\% of the aggregate shortfall of specialists in India was found in EAG states and Assam. By IPHS norms, every PHC requires to have one FHW/ANM. The shortfall of FHW/ANM has almost

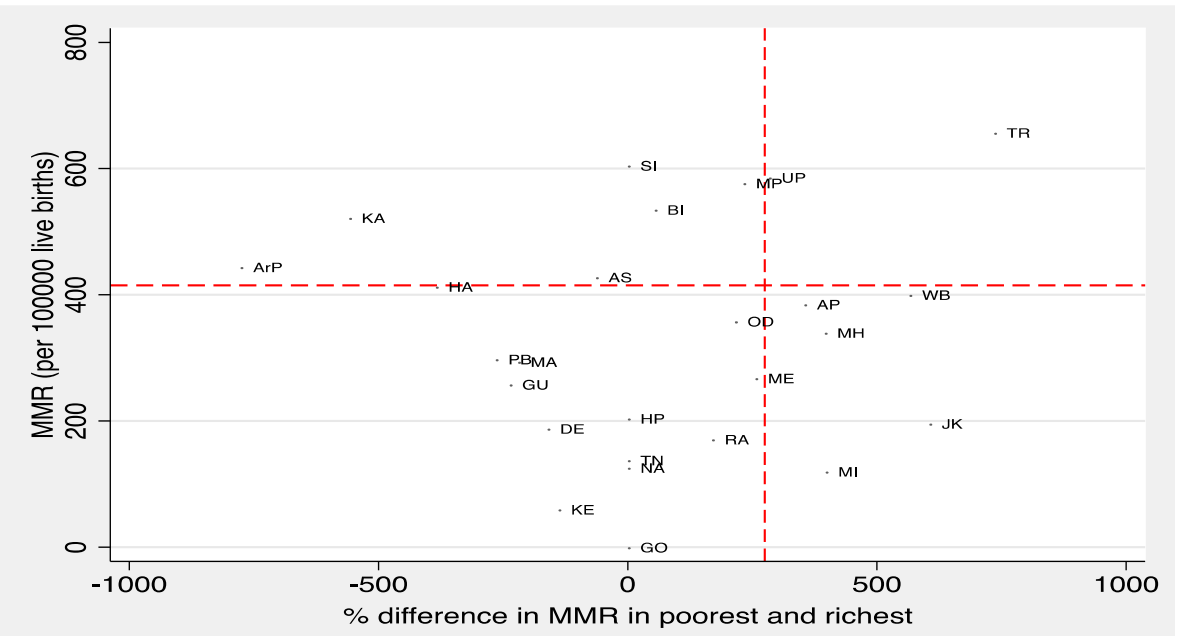

Fig. 4 Gap in MMR between poorest and richest households in India, 2015-16. Note: State codes in Supplementary Table A.2, The following states are merged together for NFHS 4: Andhra Pradesh and Telangana, Madhya Pradesh and Chhattisgarh, Bihar and Jharkhand, Uttar Pradesh and Uttarakhand. UTs are not included in this graph for their low sample size 


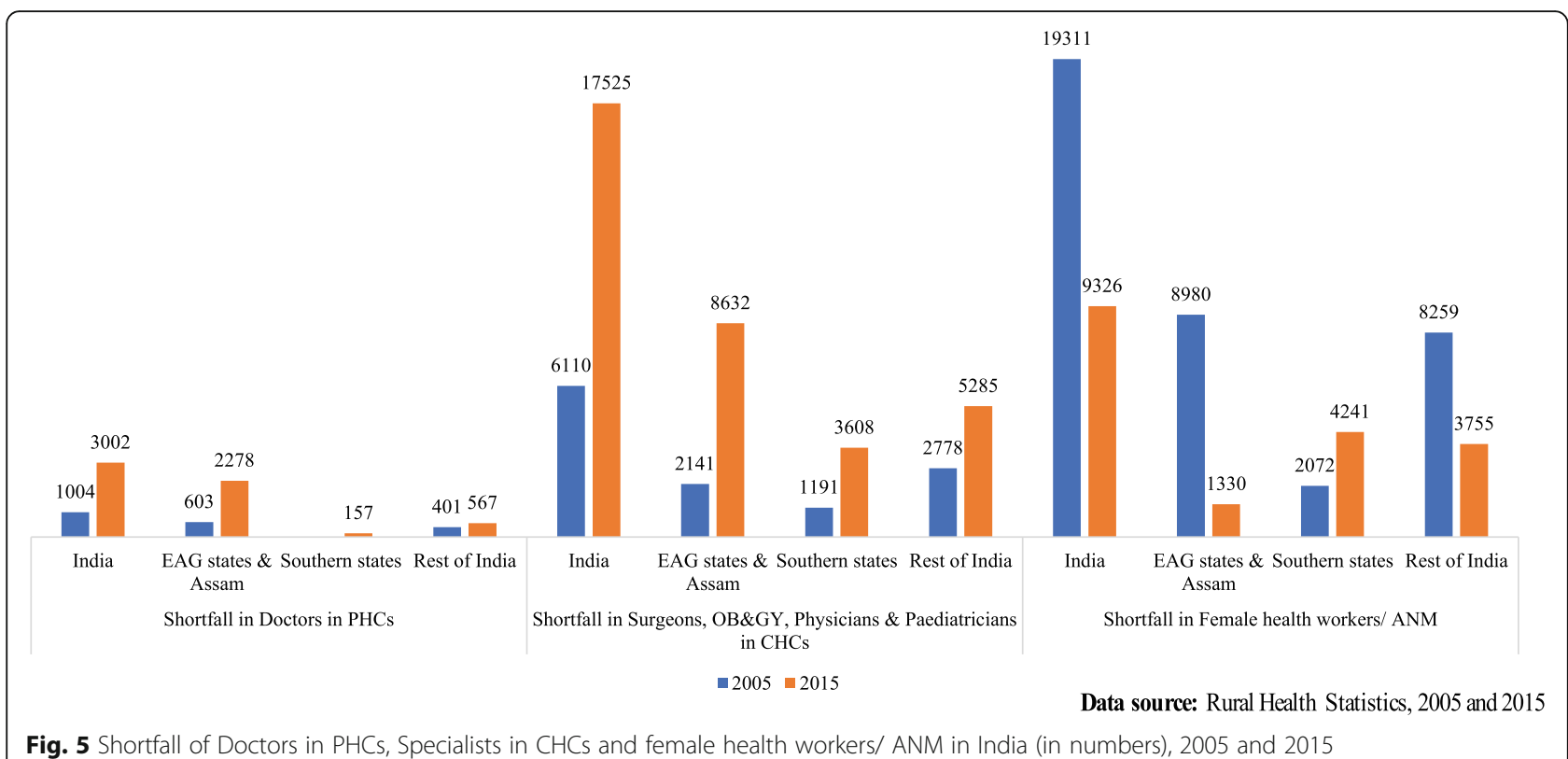

halved in India over the 2005-15 decade. The shortfall has declined in EAG states and Assam too. However, in the Southern states, the shortfall is observed to have doubled over 2005-2015.

\section{Discussion}

India has witnessed a significant decline in its Maternal Mortality Ratio (MMR) in the last 20 years. Approximately 0.14 million women were dying every year on account of complications related to pregnancy and child birth in 1990, which stands reduced by $70 \%$ [10]. In addition, India's share among global maternal deaths has declined significantly from $27.3 \%$ in 1990 to $15 \%$ [10]. Our findings also confirm that the pace of decline has accelerated since 2000. The relative decline in maternal mortality before 2000 was $32.7 \%$ whereas the decline post 2000 till 2015 was 68.7\%. Institutional delivery which was just $40 \%$ in 2005-6 has almost doubled in a decade to $78.9 \%$.

One of the strengths of this paper is an attempt to triangulate data from various sources in order to understand the trend in maternal mortality with respect to policy initiatives in a chronological order. The present paper shows that the association of household wealth status with maternal mortality is statistically not significant. Our findings suggest that the demand side financing strategies including conditional cash transfers and pro-poor policies designed to address the scourge of maternal mortality in the poorer sections of the society in rural India have an important role to play by reducing the financial barriers in accessing maternal health services. In addition, an important factor in the successful implementation of these cash based incentive schemes is the community-level involvement and the role of community health workers.

A major challenge to policy makers has been to find ways to promote access to maternal services by removing barriers in uptake of these services especially among the poor, and ensure that public subsidies are better targeted to those who need them most [11]. Both these concerns are addressed by demand side financing approaches and therefore, many countries have been experimenting with strategies like conditional cash transfers and use of vouchers to improve access to health services in general and maternal health services in particular [12-20] .

There is evidence to suggest that low access to maternity health services is an important barrier, especially for the poor, in reducing maternal mortality in many low income settings [11, 14, 21]. This holds true even in countries where maternal health care services provided by the public health sector are free at the point of use. Studies have shown that demand side financing like conditional cash transfers and use of vouchers can specifically target and incentivize poor women in order to increase affordability, accessibility, and utilization of maternal health services thereby reducing maternal mortality $[14,20,22-26]$.

The government of India has successfully implemented various conditional cash transfer schemes to remove financial barriers, increase utilization of maternal health services, and promote institutional deliveries [24, 27, 28]. In 1992, the government launched the Child Survival and Safe Motherhood (CSSM), followed by Reproductive and Child Health ( $\mathrm{RCH})$ care programmes, I and II, launched in 1997 and 2005 respectively. The Janani Suraksha Yojana (JSY), was launched during the 
National Rural Health mission, in the year 2005, with the aim to decrease maternal mortality by promoting institutional delivery through conditional cash transfer to women belonging to the poor families. Some of the centrally sponsored schemes are Janani Suraksha Yojana (JSY), Janani Shishu Suraksha Karyakram (JSSK) and Pradhan Mantri Matritva Vandana Yojana (PMMVY), Pradhan Mantri Surakshit Matritva Abhiyan (PMSMA). In addition, as health is a State subject, many States have also implemented financial incentive schemes to improve maternal health outcomes (See Table 3).

JSY was launched in 2005 by Ministry of Health and Family Welfare under the umbrella of National Rural Health Mission aimed to decrease maternal mortality by promoting institutional delivery. JSY provides incentives in the form of conditional cash transfer where money aids in changing the conduct of women who avail themselves of three antenatal check-ups and opt for institutional delivery [38]. However, eligibility criteria and monitory incentive amount varies as per the performance of the state. Accredited Social Health Activists (ASHAs) and Auxiliary Nurse Midwives (ANMs) play an important role in the successful implementation of the JSY [38]. There is a direct relation between incentivizing (like JSY) and increased use of health facilities for maternal and child health [38, 39]. JSY has expanded over the years, both in terms of coverage and budget, and has contributed significantly to the improvements in maternal health outcomes in India. This scheme covered fewer than 1 million mothers in 2005 and now covers over 10 million mothers. Similarly, its expenditure has increased from less than 0.4 billion INR (5.5 million USD) to about 18 billion INR (245 million USD) currently [10].

Subsequently, building on JSY, another centrally implemented scheme JSSK was launched in 2011, which mainly focused on reducing out of pocket expenditure among pregnant women [40]. As a result of JSY \& JSSK, utilization of public health services has increased significantly by pregnant women over the years. More recently, Pradhan Mantri Surakshit Matritva Abhiyan (PMSMA) was launched in 2016 which entitles all pregnant women to the comprehensive package including quality antenatal care, free of cost in the public health facility. In just 13 months, PMSMA successfully achieved 13 million antenatal check-ups and resulted in diagnosis of 0.65 million high-risk pregnancies. In addition to the centrally sponsored schemes, various states have also implemented their own financial incentive schemes (See Table 3). Various studies too support our conclusion that conditional cash transfers removed financial barriers to access, improved utilisation of maternal health services, and promoted institutional deliveries in India $[25,27,29,38-40]$.
Our results also indicate the importance of ancillary factors and broader social determinants of maternal health in contributing to the reduction in maternal mortality and morbidity. For example, India has witnessed increase in contraceptive use resulting in decrease in unmet need. Increasing contraceptive use contributes to a decline in high parity births that elevate the risk of maternal mortality [41]. Similarly, poor nutritional status and Vitamin A deficiency among pregnant women can lead to chronic conditions like eclampsia, preeclampsia, ante-partum and post-partum haemorrhage, thus being a contributory factor for maternal mortality [42]. Our findings suggest significant reduction in nutritional deficiency anaemia among women over the years. India has also witnessed reduction in child marriages among women. Early marriages have a higher risk of intimate partner violence, HIV/STIs, depression, and contribute to maternal morbidity and mortality [43]. Also, female literacy has dramatically increased from 32.3 in 1991 to 65.8 in 2018 [44]. Finally, households below poverty line have halved from 45.3 in 1993 to 21.9 in 2012 [45]. In terms of HDI, India's value increased from 0.43 to 0.65 from 1990 to 2018 and India now ranks at 129 out of 189 countries in 2018 [46]. Thus, as a result of these conditional cash transfer schemes, there has been improved utilization of maternal health services, including births in health facility, which have contributed significantly to the reduction in the share of MMR. In addition, targeting ancillary and broader social determinants of maternal health along with various social marketing strategies has further accelerated the trend of declining maternal mortality in India.

Although India is moving in the right direction, and has achieved considerable decline in maternal mortality, it needs further intense efforts. Compared to other countries in the region, India is only better than Nepal, Bhutan and Afghanistan in terms of maternal mortality and at par with Bangladesh and Pakistan. It still lags behind other regional countries like Indonesia, Thailand, Sri Lanka and China. In addition, as our analysis reveals, the gains in terms of maternal mortality have been unevenly distributed in India. There exits huge inequalities in maternal mortality and other maternal health outcomes between EAG states and socio-economic groups within the states. For example, maternal mortality varies from less than 70/ 100000 live births in states like Kerala, Maharashtra, Tamil Nadu to over 200 in EAG states like UP and Assam. In addition, our multivariate logistic analysis reveals that women belonging to poorest households, illiterate or educated below secondary schooling, without any health insurance coverage and residing in EAG states have a significant higher maternal mortality. Although the female literacy has increased for India as a whole, the gap between the EAG and non-EAG states is over 13\%. 
Table 3 Summary of major Demand side financing schemes for maternal health in India

\begin{tabular}{|c|c|c|c|c|}
\hline Scheme name & $\begin{array}{l}\text { Launch } \\
\text { year }\end{array}$ & Location & Details & Impact \\
\hline $\begin{array}{l}\text { Dr. Muthulakhsmi } \\
\text { Reddy Maternity } \\
\text { Benefit scheme }\end{array}$ & 1987 & Tamil Nadu & $\begin{array}{l}\text { Financial assistance: INR18,000 /- (245 USD) } \\
\text { Instalments: } 2 \\
\text { Eligibility: minimum } 19 \text { years, BPL women in the } \\
\text { State } \\
\text { Conditionality: restricted for two deliveries and } \\
\text { delivered in a government institution }\end{array}$ & $\begin{array}{l}\text { This was one of the pioneering maternity benefit } \\
\text { schemes to influence health seeking behaviour } \\
\text { away from home care and ensure increased } \\
\text { survival of mothers and children [29]. This scheme } \\
\text { has been combined with PMMVY in Tamil Nadu. }\end{array}$ \\
\hline Sukhibhava & 1999 & $\begin{array}{l}\text { Andhra } \\
\text { Pradesh }\end{array}$ & $\begin{array}{l}\text { Integrated with JSY } \\
\text { Financial assistance: INR300 (4 USD) for first two } \\
\text { deliveries } \\
\text { Bank payment: "Sukhibhava" account }\end{array}$ & $\begin{array}{l}\text { This scheme provides evidence that state-level } \\
\text { customization of JSY can benefit in addressing } \\
\text { wide regional disparities in maternal and child } \\
\text { health outcomes. }\end{array}$ \\
\hline $\begin{array}{l}\text { Janani Suraksha } \\
\text { Yojana (JSY) }\end{array}$ & 2005 & Central & $\begin{array}{l}\text { Eligibility: poor pregnant woman from low } \\
\text { performing states (LPS) and high performing states } \\
\text { (HPS). All births in LPS and upto } 2 \text { live births in } \\
\text { HPS. } \\
\text { In LPS all pregnant women delivering in } \\
\text { Government health centres or accredited private } \\
\text { institutions are eligible. } \\
\text { In HPS BPL pregnant women, aged } 19 \text { years and } \\
\text { above are eligible for cash assistance. } \\
\text { LPS states: Uttar Pradesh, Uttaranchal, Bihar, }\end{array}$ & $\begin{array}{l}\text { Resulted in significant increase in ante-natal care } \\
\text { and institutional delivery. } \\
\text { Associated with reduction of 3-4 perinatal deaths } \\
\text { per } 1000 \text { pregnancies and } 3 \text { neonatal deaths per } \\
1000 \text { livebirths [27]. } \\
\text { Some unintended effects report JSY beneficiaries } \\
\text { from LPS are } 12 \% \text { more likely to use } \\
\text { contraception, } 8 \% \text { more likely to initiate early } \\
\text { breastfeeding and } 6 \% \text { more likely to get their } \\
\text { postnatal check-up than mothers from HPS [30]. }\end{array}$ \\
\hline
\end{tabular}

Janani Evam Bal $2006 \quad$ Bihar
Suraksha Yojna

Chiranjeevi $2006 \quad$ Gujarat
Yojana

Sambhav voucher 2007 scheme Jharkhand, Madhya Pradesh, Chhattisgarh, Assam, Rajasthan, Orissa and Jammu and Kashmir. Rest HPS.

Financial assistance: LPS rural areas and urban areas: INR1400 (19.1 USD), INR1000 (13.6 USD) HPS rural areas and urban areas: INR1000 (13.6 USD), INR600 (8.2 USD)

Financial incentive to ASHA workers: LPS of INR 600 (8.2 USD) in rural areas and INR 200 (2.7 USD) in urban areas.

Integrates cash assistance with institutional care Eligibility: BPL women

Financial assistance: INR 1400 (19.1 USD) in rural areas and INR 1000 (13.6 USD) in urban areas paid for birth either in a government or private hospital

Eligibility: BPL women

Financial assistance: INR 200 (2.7 USD) as financial assistance+ out of pocket transport cost with INR 50 (67 cents) to the attendant.

In addition, fixed incentive for private doctors providing gynaecological services. The state pays private doctors a fixed sum of INR6000 (81.8 USD) per 100 births among eligible women living below poverty line (BPL) or belonging to scheduled tribes (ST).

Uttarakhand/ Voucher scheme in collaboration with USAID.

Uttar Pradesh Institutions are also incentivized so can women avail private facilities.

Eligibility for vouchers: Women from BPL family Services include antenatal care, institution birth, post-natal care and family planning services. Accredited private facilities provide services and en-cash the voucher

State-sponsored conditional cash transfer maternal benefit scheme to increase utilization of maternal and child healthcare services. Incentive: INR6000 (81.8 USD) over a period of 18 months in instalments.

Eligibility: all pregnant and lactating mothers of 19 years and above for the first two births.
ASHA intervention has been effective for the employment of JBSY. It has helped in bridging gaps in the knowledge base of the target communities.

An innovative scheme which increased institutional delivery and provided access to quality maternal care among the poor. Lesser maternal and new-born deaths were observed as a result of this scheme [31].

This is a standalone provider led scheme. Most beneficiaries claimed to have had access to quality health services under this scheme. The effectiveness of the scheme improved due to the involvement of Community Health Volunteers (CHVs). Most urban slum dwellers put their confidence in the scheme mainly due to the CHVs.

Scheme successful in improving antenatal care, exclusive breast feeding, full immunization, etc. A total number of 547,000 mothers were beneficiaries for the financial year 2017-2018 with a budget allocation of INR 3.8 billion (52 million USD).

The state is well known for implementing maternal health and nutrition programmes [32]. 
Table 3 Summary of major Demand side financing schemes for maternal health in India (Continued)

\begin{tabular}{|c|c|c|c|}
\hline Scheme name & $\begin{array}{l}\text { Launch } \\
\text { year }\end{array}$ & Location & Details \\
\hline $\begin{array}{l}\text { Janani Shishu } \\
\text { Suraksha } \\
\text { Karyakram (JSSK) }\end{array}$ & 2011 & Central & $\begin{array}{l}\text { Eligibility: All pregnant women provided with free } \\
\text { delivery including caesarean section in public } \\
\text { health facilities. } \\
\text { Entitlements: free drugs and consumables; free } \\
\text { investigations blood transfusion if needed; free } \\
\text { diet; and free return transport. } \\
\text { 2014: entitlements extended to all antenatal \&post- } \\
\text { natal complications of pregnancy; and all sick new- } \\
\text { borns and infants (up to } 1 \text { year of age). }\end{array}$ \\
\hline
\end{tabular}

$\begin{array}{ll}\text { Pradhan Mantri } 2016 \quad \text { Central } & \text { Comprehensive antenatal services to pregnant } \\ \text { Surakshit Matritva } & \text { women } \\ \text { Abhiyan (PMSMA) } & \text { Eligibility: } 2 \text { nd and } 3 \text { rd trimester women on the 9th } \\ & \text { day of every month } \\ & \text { No. of facilities: } 17,217 \\ & \text { Private sector involvement: Prime Minister of India } \\ & \text { appeal to doctors to contribute } 12 \text { days in a year. }\end{array}$

This scheme promotes free services to pregnant women and sick neonates.

In 2019-2020, 9.2 million pregnant women were provided free medicines, 6.2 million free diet, 9.6 million free diagnostics, 3.8 million free transport. Same holds true for sick infants.

Significant increase in ante-natal care check-ups and institutional delivery in public facilities due to JSSK [33]; and improved access to level III NICU care among the poor thus reducing preterm mortality rates [34].

In the first year of launch, a total of 3,090,270 pregnant women received ANC. More than one crore antenatal check-ups have been conducted till date.

While all States/ UTs have made significant efforts to reach out to pregnant women, Rajasthan has largest number of check-ups among the Empowered Action Group States.

Includes comprehensive ANC, early identification and follow-up of high risk pregnancies. Identifying high risk pregnancies is necessary step in reducing avoidable maternal and infant deaths [35]. To detect high risk pregnancies, 84 lakh haemoglobin tests, 55 lakh HIV tests, 41 lakh tests for gestational diabetes, 33 lakh tests for syphilis and more than 15 lakh ultrasounds have been performed.

Over 5.50 lakh pregnant women were identified as high risk pregnancies and referred to a specialist or a higher health facility for appropriate care.

\begin{tabular}{|c|c|c|c|}
\hline $\begin{array}{l}\text { Pradhan Mantri } \\
\text { Matrutva Vandan } \\
\text { Yojana (PMMVY) }\end{array}$ & Central & $\begin{array}{l}\text { Implementation: Integrated Child Development } \\
\text { Services. } \\
\text { Financial assistance: INR } 5000 \text { ( } 68.2 \text { USD) in Three } \\
\text { Instalments for the First Live Child. }\end{array}$ & $\begin{array}{l}\text { From } 2017 \text { to } 2020,1,36,80,531 \text { beneficiaries [36]. } \\
\text { However, this scheme is criticized for excluding } \\
\text { women with more than } 1 \text { children. } \\
\text { A survey showed that only } 22 \% \text { pregnant and } \\
\text { lactating women were covered under this scheme } \\
\text { [37]. }\end{array}$ \\
\hline
\end{tabular}

1 USD = 73.33 INR as on 8th January, 2021 obtainable from https://www.imf.org/external/np/fin/data/rms_mth.aspx?SelectDate=2020-11-30\&reportType=REP

Policy makers need to prioritise underperforming states and socio-economic groups within the states where intense efforts need to be expanded. In addition, it is necessary to address supply-side factors hand in hand with demand-side measures. Primary Health Centres (PHCs) which are a backbone for providing basic health services including maternal health services to the rural population, have been neglected historically among the EAG states and Assam. The gap in terms of PHC shortfall between these states and Southern states has been observed since 2004, and this gap has dramatically increased over the years. The same holds true with respect to shortfall in terms of human resource availability i.e. shortfall of PHC doctors; Obstetricians, Physicians and Paediatricians have drastically increased in EAG states from 2005 to 2015.

A major concern still remains in terms of inadequate health care financing [47] as India's government health expenditure as a percentage of GDP is a meagre $1.28 \%$.
This is one of the lowest government health expenditures among countries in the region including Nepal, Sri Lanka, Thailand, and Indonesia. Such low public health expenditures coupled with high out of pocket payments (67.8\% of total health expenditure) need to be addressed before India makes further progress. Together, demandside and supply-side measures mediated by contextual factors are likely to improve maternal health outcomes in underperforming states of India.

\section{Conclusions}

India has been able to drastically reduce its maternal mortality and improve maternal health outcomes in recent years. This impressive performance can be attributed to the various policies and cash incentive schemes launched during the launch of National Rural Heath Mission in 2005. Our findings suggest that Wealth Index was not found to be statistically significant in either group of states, which supports our conclusion that any 
effective pro-poor policy aims to minimise the impact of household's wealth status on adverse maternal health outcomes by reducing the financial barrier to access maternal health services. In addition to the more targeted approach, India has also attempted to address broader social determinants of maternal health which have contributed to improving maternal outcomes. However, the distribution of these gains is uneven across states and socio-economic groups. Along with demand side financing schemes, supply side measures are necessary to accelerate the gains in maternal outcomes in the underperforming states.

\section{Abbreviations}

ANC: Ante-natal care; ANM: Auxiliary Nurse midwives; ASHA: Accredited Social Health Activist; CHC: Community Health Centre; CSSM: Child Survival and Safe Motherhood; FHW: Female Health worker; HDI: Human Development Index; IPHS: Indian Public Health Standard; JSY: Janani Suraksha Yojana; JSSK: Janani Shishu Suraksha Karyakram; MDGs: Millennium Development Goals; MMR: Maternal Mortality Ratio; NFHS: National Family Health Survey; PHC: Primary Health Care Centre; PMMVY: Pradhan Mantri Matritva Vandana Yojana; PMSMA: Pradhan Mantri Surakshit Matritva Abhiyan; RCH: Reproductive and Child Health; SDGs: Sustainable Development Goals; SRS: Sample Registration System; UNICEF: United Nations Children's Fund; WHO: World Health Organization

\section{Supplementary Information}

The online version contains supplementary material available at https://doi. org/10.1186/s12884-021-03839-w.

Additional file 1: Table A.1. Variables used for analysis. This Table provides the details of the variables used for the analysis in the manuscript. Figure A.1. Trend in shortfall in primary health care facilities in rural India, 2004-2018. This figure provides the shortfall in PHC facilities among EAG States including Assam, Southern States and rest of India.

Table A.2. State codes. The codes for states of India that have been used in the analysis are provided in this table.

\section{Acknowledgements}

The authors are extremely grateful to the two anonymous reviewers for their comments and edits on the earlier draft of the manuscript which has improved the quality of the revised submission.

\section{Authors' contributions}

$M B$ and $L K D$ were responsible for the planning and design of this manuscript. KB, MR, AB, PD were involved with the analysis of the data. All authors have contributed to the writing and editing of this paper. All authors have seen and approved the final version of this manuscript.

\section{Funding}

None.

\section{Availability of data and materials}

The datasets analysed during the current study are from National Family Health Survey (NFHS) for India. The data is freely available from the DHS website The DHS Program - India: Standard DHS, 2015-16 Dataset.

\section{Declarations}

\section{Ethics approval and consent to participate}

Ethical approval for this study was not necessary as it is based on analysis of secondary data available in the public domain. However, the NHFS team had obtained written consent from all participants. In addition, the ethical clearance were obtained by the NHFS team and cleared by the Institutional Review Board under ICF Project Number: 631561.0.000.00.071.01.
Consent for publication

Not applicable.

\section{Competing interests}

None.

\section{Author details}

${ }^{1}$ Department of Health Policy, London School of Economics and Political Science, Houghton Street, London WC2A 2AE, UK. ${ }^{2}$ International Institute for Population Sciences, Mumbai, India. ${ }^{3}$ Department of Statistics, Mizoram University, Pachhunga University College Campus, Aizawl, Mizoram, India. ${ }^{4}$ School of Health Systems Studies, Tata Institute of Social Sciences, Mumbai, India.

Received: 21 August 2020 Accepted: 28 April 2021

Published online: 19 May 2021

\section{References}

1. Alkema L, Chou D, Hogan D, Zhang S, Moller AB, Gemmill A, et al. Global, regional, and national levels and trends in maternal mortality between 1990 and 2015, with scenario-based projections to 2030: a systematic analysis by the UN Maternal Mortality Estimation Inter-Agency Group. Lancet. 2016; 387(10017):462-74. https://doi.org/10.1016/S0140-6736(15)00838-7.

2. WHO. The global strategy for women's, children's and adolescent's health (2016-2030). 2015. https://www.who.int/life-course/partners/global-strategy/ globalstrategyreport2016-2030-lowres.pdf.

3. Ronsmans C, Graham WJ. Lancet maternal survival series steering group. Maternal mortality: who, when, where, and why. Lancet. 2006;368(9542): 1189-200. https://doi.org/10.1016/S0140-6736(06)69380-X.

4. WHO, UNICEF, UNFPA, World Bank group, UNDP. Trends in maternal mortality : 1990 to 2015. 2015. https://apps.who.int/iris/bitstream/handle/1 0665/194254/9789241565141_eng.pdf;jsessionid=9CCCC9E15E0EE1E21 BCB424963C5E660? sequence $=1$.

5. Office of Registrar General \& Census Commissioner. Special bulletin on maternal mortality in India. New Delhi: Office of the Registrar General; 2013.

6. Bullough C, Meda N, Makowiecka K, Ronsmans C, Achadi EL, Hussein J. Current strategies for the reduction of maternal mortality. BJOG An Int J Obstet Gynaecol. 2005;112(9):1180-8. https://doi.org/10.1111/j.1471-0528.2 005.00718.x.

7. Ministry of Health and Family Welfare. Maternal \& adolescent healthcare. In: Annual report 2014-15; 2015. https://main.mohfw.gov.in/sites/default/files/ 03Chapter.pdf.

8. Singh PK. India has achieved groundbreaking success in reducing maternal mortality. New Delhi: WHO Regional Director for South-East Asia; 2018.

9. International Institute for Population Sciences (IIPS), ICF. National Family Health Survey (NFHS-4), 2015-16: India. Mumbai: IIPS; 2017.

10. Ministry of Health and Family Welfare. Maternal \& adolescent healthcare. 2018

11. Bohren MA, Hunter EC, Munthe-Kaas HM, Souza JP, Vogel JP, Gülmezoglu AM. Facilitators and barriers to facility-based delivery in low- and middleincome countries: a qualitative evidence synthesis. Reprod Health. 2014;11: $1-17$.

12. Hunter BM, Harrison S, Portela A, Bick D. The effects of cash transfers and vouchers on the use and quality of maternity care services: a systematic review. PLOS One. 2017;12(3). https://doi.org/10.1371/journal.pone.0173068.

13. Glassman A, Duran D, Fleisher L, Singer D, Sturke R, Angeles G, et al. Impact of conditional cash transfers on maternal and newborn health. J Heal Popul Nutr. 2013;31(4 SUPPL.2). https://doi.org/10.3329/jhpn.v31i4.2359.

14. Murray SF, Hunter BM, Bisht R, Ensor T, Bick D. Demand-side financing measures to increase maternal health service utilisation and improve health outcomes: a systematic review of evidence from low- and middle-income countries. JBI Database Syst Rev Implement Rep. 2012;10:4165-567. https:// doi.org/10.11124/jbisrir-2012-408.

15. Gupta I, William J, Rudra S. Demand side financing in health. How far can it address the issue of low utilization in developing countries? 2010. http:// www.who.int/entity/healthsystems/topics/financing/healthreport/27DSF.pdf.

16. de Brauw A, Peterman A. Can conditional cash transfers improve maternal health care? Evidence from El Salvador's "Comunidades Solidarias Rurales" program. Health Econ. 2020;29(6):700-15. https://doi.org/10.1002/hec.4012.

17. Dennis ML, Abuya T, Campbell OMR, Benova L, Baschieri A, Quartagno M, et al. Evaluating the impact of a maternal health voucher programme on 
service use before and after the introduction of free maternity services in Kenya: a quasi-experimental study. BMJ Glob Heal. 2018;3(2):1-11. https:// doi.org/10.1136/bmjgh-2018-000726.

18. Mahmood SS, Amos M, Hoque S, Mia MN, Chowdhury AH, Hanifi SMA, et al. Does healthcare voucher provision improve utilisation in the continuum of maternal care for poor pregnant women? Experience from Bangladesh. Glob Health Action. 2019;12(1):1701324. https://doi.org/10.1080/16549716.2 019.1701324.

19. Lagarde M, Haines A, Palmer N. The impact of conditional cash transfers on health outcomes and use of health services in low and middle income countries (review). Cochrane Libr. 2009;4. https://doi.org/10.1002/14651858. CD008137.

20. Bhatia MR, Gorter AC. Improving access to reproductive and child health services in developing countries: are competitive voucher schemes an option? J Int Dev. 2007;19(7):975-81. https://doi.org/10.1002/jid.1361.

21. Ensor T. Developing health insurance in transitional Asia. Soc Sci Med. 1999; 48(7):871-9. https://doi.org/10.1016/S0277-9536(98)00389-X.

22. Grant D. Physician financial incentives and cesarean delivery: new conclusions from the healthcare cost and utilization project. J Health Econ. 2009;28(1):244-50. https://doi.org/10.1016/j.jhealeco.2008.09.005.

23. Bhatia M. The Indian Health Care System, 2015. In: Mossialos E, Wenzl M, Osborn R, Sarnak D, editors. 2015 International Profiles Of Health Care Systems. Washinghton D.C.: London School of Economics and Political Science and The Commonwealth Fund; 2016. p. 77-85.

24. De Costa A, Patil R, Kushwah SS, Diwan VK. Financial incentives to influence maternal mortality in a low-income setting: making available "money to transport" - experiences from Amarpatan, India. Glob Health Action. 2009;2: $1-9$.

25. Higgs ES, Stammer E, Roth R, Balster RL. Evidence acquisition and evaluation for evidence summit on enhancing provision and use of maternal health services through financial incentives. J Heal Popul Nutr. 2013;31(4 SUPPL.2): S23-35. https://doi.org/10.3329//hpn.v31i4.2357.

26. Christian P, Shaikh S, Shamim AA, Mehra S, Wu L, Mitra M, et al. Effect of fortified complementary food supplementation on child growth in rural Bangladesh : a cluster-randomized trial. Int J Epidemiol. 2015;44(6):1862-76. https://doi.org/10.1093/ije/dyv155.

27. Lim SS, Dandona L, Hoisington JA, James SL, Hogan MC, Gakidou E. India's Janani Suraksha Yojana, a conditional cash transfer programme to increase births in health facilities: an impact evaluation. Lancet. 2010;375(9730):200923. https://doi.org/10.1016/S0140-6736(10)60744-1.

28. Paul VK. India: conditional cash transfers for in-facility deliveries. Lancet. 2010:9730(9730):1943-4. https://doi.org/10.1016/S0140-6736(10)60901-4.

29. Srinivasan R, Ganesan SK, Premkumar PS, Kang G. Influence of publicly funded conditional cash transfer programms on utilization patterns of healthcare services for acute childhood illness. Int Health. 2020;12(4):339-43. https://doi.org/10.1093/inthealth/ihz099.

30. Sen S, Chatterjee S, Kanti khan P, Mohanty SK. Unintended Effects of Janani Suraksha Yojana on Maternal Care in India. SSM - Popul Heal. 2020;11: 100619

31. Mavalankar D, Singh A, Patel SR, Desai A, Singh PV. Saving mothers and newborns through an innovative partnership with private sector obstetricians: Chiranjeevi scheme of Gujarat, India. Int J Gynecol Obstet. 2009;107:271-6.

32. Mishra NR, Mohanty SK, Mittra D, Shah M, Meitei WB. Projecting stunting and wasting under alternative scenarios in Odisha, India, 2015-2030: a Lives Saved Tool (LiST)- based approach. BMJ Open. 2019;9:1-12.

33. Government of India, Ministry of Health and Family Welfare. Janani Shishu Suraksha Karyakaram. New Delhi: Press Information Bureau; 2020.

34. Kakkad KM, Patel MS, Patel S. Pritesh. Effect of "Janani Shishu Suraksha Karyakram" - a Government Health Beneficiary Scheme - on Admission Rate and Clinical Outcome in NICU in a Tertiary Care Hospital. Natl J Community Med. 2014;5:118-21.

35. Ministry of Health and Family Welfare. Pradhan Mantri Surakshit Matritva Abhiyan (PMSMA) Crosses One Crore Mark! PIB Delhi. 2018

36. Government of India, Ministry of Women and Child Development. Maternity Benefit Disbursed to 1.36 Crore Beneficiaries under PMMVY. New Delhi: Press Information Bureau; 2020

37. Dreze J, Khera R, Somanchi A. Jaccha Baccha Survey; 2019.

38. Panja TK, Mukhopadhyay DK, Sinha N, Saren AB, Sinhababu A, Biswas AB. Are institutional deliveries promoted by Janani Suraksha Yojana in a district of West Bengal, India? Indian J Public Health. 2012;56:69.
39. Gupta SK, Pal DK, Tiwari R, Garg R, Shrivastava AK, Sarawagi R, et al. Impact of Janani Suraksha Yojana on institutional delivery rate and maternal morbidity and mortality: an observational study in India. J Health Popul Nutr. 2012;30:464-71.

40. Tyagi U, Pattabi K, Kaur P. Utilization of services under Janani Shishu Suraksha Karyakram for institutional deliveries in the public sector facilities, Sirmaur District, Himachal Pradesh, India. Indian J Community Med. 2016; 41(1):65-8. https://doi.org/10.4103/0970-0218.170992.

41. Stover J, Ross J. How contraceptive use affects maternal mortality; 2008.

42. Brabin BJ, Hakimi M, Pelletier D. An analysis of anemia and pregnancyrelated maternal mortality. J Nutr. 2001;131(2S-2):604S-14S.

43. Mehra D, Sarkar A, Sreenath P, Behera J, Mehra S. Effectiveness of a community based intervention to delay early marriage, early pregnancy and improve school retention among adolescents in India. BMC Public Health. 2018;18:1-13.

44. World Bank (2020). World Bank data on literacy rate, India. World Bank data available here).

45. Government of India. India in figures 2018. 2018. http://mospinic.in/sites/ default/files/publication_reports/India_in_figures-2018_rev.pdf.

46. UNDP. Human development report 2019: inequalities in human development in the 21st century. New York: UNDP; 2019. http://hdr.undp. org/sites/default/files/hdr2019.pdf

47. Bhatia M, Singh D.P. Health sector allocation in India's budget (2021-2022): a trick or a treat? Accepted for publication in Int J Community Soc Dev. 2021; 3:2.

\section{Publisher's Note}

Springer Nature remains neutral with regard to jurisdictional claims in published maps and institutional affiliations.
Ready to submit your research? Choose BMC and benefit from:

- fast, convenient online submission

- thorough peer review by experienced researchers in your field

- rapid publication on acceptance

- support for research data, including large and complex data types

- gold Open Access which fosters wider collaboration and increased citations

- maximum visibility for your research: over $100 \mathrm{M}$ website views per year

At BMC, research is always in progress.

Learn more biomedcentral.com/submissions 